\title{
IMPROVEMENT OF POWER QUALITY AND SPEED REGULATION OF A BLDC MOTOR DRIVE USING AN INTERLEAVED CONVERTER
}

\author{
Shreekara S Hegde, \\ MTech PE \\ Department of Electrical and Electronics Engineering \\ BMS College of Engineering, Bangalore
}

\begin{abstract}
Interleaved boost converters are preferred for applications which require high efficiency, faster dynamics, less inductor current ripple and high power density. In this paper, an interleaved boost converter is in order to enhance the power quality $(\mathrm{PQ})$. This converter drives a Permanent Magnet Brushless Direct Current (PMBLDC) Motor. The Converter is supplied power through a single phase $\mathrm{AC}$ mains supply rectified by a Diode bridge rectifier. The converter supplies DC link voltage to the three phase Voltage Source Inverter (VSI). The inverter goes about as an electronic commutator for the Brushless Direct Current motor driving the Air conditioner compressor. Power Factor correction is done using PI controllers. Speed of the Brushless Direct Current motor is regulated by adjusting the output voltage of the converter. The BLDC motor drive presented is designed and the performance analysis of the drive is done using MATLABSIMULINK software.
\end{abstract}

Keywords-MATLAB-SIMULINK, Permanent Magnet Brushless DC Motor (PMBLDCM), power quality (PQ), Voltage Source Inverter (VSI).

\section{INTRODUCTION}

Permanent magnet Brushless Direct Current (PMBLDC) motors are classified as one of the types of synchronous motors [1,2]. Ragu S. in "Simulation of Speed Control of Brushless DC Motor for four Quadrant Operation" describes the basic structure of a BLDC motor. The armature windings i.e. the stator windings present in the slots are cut around the poles of the stator (2014) [3]. The armature also has stacked steel laminations [3,4]. The rotor consists of permanent magnets with north and south poles alternatively mounted [3]. This motor has the field which is given by permanent magnets. Hence, this Permanent magnet AC (PMAC) motor has higher efficiency compared to other motors. Brushless Direct Current motors are considered to be one of the promising electrical motors due to increased efficiency, compact size, higher reliability, noiseless operation and lower maintenance [1,2,3,4]. Additionally, in recent times permanent magnets are also less expensive. Arunkumar et al in "A Review Paper on Torque Ripple

\author{
A.N.Nagashree \\ Associate professor \\ Department of Electrical and Electronics Engineering \\ BMS College of Engineering, Bangalore
}

Reduction and Power Quality Improvement in Brushless DC Motor Drives" emphasizes about how BLDC motors are better compared to others motors for applications in home appliances, medical consumer electronics, automotive sector, aerospace and industries due to their advantages (2014)[4]. This motor is powered by a three phase inverter and it is controlled by the position of the rotor $[1,2,3,4]$. There are many sensors which are used to find the position of the rotor shaft [1,2]. Shivani Mishra et al in "Speed Control of PMBLDC Motor With the help of PI controller" tells about different position sensors used in detecting the rotor shaft position i.e.Optical encoders, resolvers and Hall sensors are utilized in detecting the angle of rotor shaft w.r.t. a reference axis (2015)[5]. Based on the position of the permanent magnet acting like a rotor, the three Hall sensors give a particular signal. These signals are used to trigger the power electronic switches of the inverter. Hence quasi rectangular current signals with a phase shift of $120^{\circ}$ are generated. These signals power the BLDC motor. Hence, this is a motor which is rotated by electronic means $[6,7,8,9]$. The starting characteristics of a BLDC motor are similar to that of the DC series motors [6]. The speedregulation characteristics are identical with that of the DC shunt motors [6].

The Air-Conditioning system with BLDC motor has several merits such as has long life, low running cost, lesser maintenance and noiseless operation compared to other motors. [7]. When air-conditioner compressor is loaded to BLDC motor, it helps in the increase of the efficiency of the system [7,8]. The speed of the BLDC motor is controlled to rotate with a speed which is equal to the reference speed [7,8]. Hence, the control of the temperature is done at the zone of the Air-Conditioning system.

Conventional DC machines have mechanical brushes and commutator assembly and hence have problems like wear and tear of the brushes [9]. This problem does not exist in BLDC motor due to the absence of brushes. Therefore, mechanical commutation is not used for BLDC motors and are powered electronically [9].

The proposed drive is fed through AC mains supply. It is rectified using bridge rectifier which gives a Pulsating DC voltage. Athiyaman S. et al in "Power quality 
improvement in PMBLDC drive using PFC Sepic Converter for Air Conditioner" talks about the addition of a filter capacitor in order to remove the pulsations in the voltage at the output of the bridge rectifier (2013)[10]. Inclusion of a capacitor as a filter results in pulsed current of a very high amplitude due to the charging of the capacitor which can't be controlled. This leads to reduction of power factor which degrades the power quality at $\mathrm{AC}$ mains and there will be increase in the Total Harmonic Distortion (THD) of the supply current $[7,8,10]$. Hence, there is a need to enhance the power factor so that good quality of power at can be maintained at AC mains [7,8]. The power quality should be such that its parameters should be accepted by international standards of PQ i.e. IEC 61000-3-2 [7, 8, 10, 11]. Stephy Mathew et al in "Review of DC-DC converters for PFC in SMPS" explains about various topologies of Switched Mode Power Converters which are used in improving the Power Factor (2017)[12]. Buck converter does not have the source of the power electronic switch connected to ground. Hence, design of gate driver is difficult. While Boos t converter has more inductor current and output voltage ripple. Converters like Buck-Boost and Cuk face the drawback of reverse polarity of capacitor voltage [13]. Zeta converter has disadvantages of higher Electromagnetic Interference (EMI) because of power electronic switch in series to supply[13]. These result in difficulties in designing a proper gate driver circuit. An Interleaved boost converter provides a solution for the above problems with lesser inductor current ripple and comparatively simple gate driver design.

In the present work, an Interleaved boost converter is utilized for the proposed drive circuit. The converter operates in Continuous Conduction mode (CCM). Thiyagarajan et al in "Analysis and comparison on conventional and Interleaved DC-DC boost converter" emphasizes on the advantages of interleaved boost converters i.e. continuous input current, reduced ripple of input inductor, lesser ripple of output capacitor voltage and component size reduction when compared to the conventional converters (2014)[14]. The BLDC motor's speed is controlled by controlling the output voltage of the converter $[15,16,17]$. This acts as the DC link voltage for the Three Phase Inverter to obtain the desired speed $[15,16,17]$. The design of the BLDC drive and its performance assessment is presented in this paper for the compressor application used in air-conditioning systems.

\section{PROPOSED VOLTAGE CONTROLLED PFC SYSTEM}

Fig.1 shows the proposed voltage controlled drive for enhancement of power quality. The mains supply of $220 \mathrm{~V}$ is stepped down to $110 \mathrm{~V}$ using a stepdown transformer. This voltage is rectified by the usage of a bridge rectifier consisting of 4 diodes which results in a pulsating wave having average voltage of $99 \mathrm{~V}$. The output of the bridge rectifier provides the input to the interleaved boost converter. The converter boosts the input voltage of $99 \mathrm{~V}$ to a $300 \mathrm{~V}$. The voltage across the output capacitor acts as the DC link voltage which excites the Three Phase Inverter. The inverter is operated in $120^{\circ}$ conduction mode which produces quasi rectangular currents to excite the BLDC motor. This motor works on the feedback principle where Hall sensors finds out the position of rotor. The switching sequence of the Voltage Source Inverter is determined by these sensors and the corresponding windings of the motor are excited based on the output of the Hall sensors.

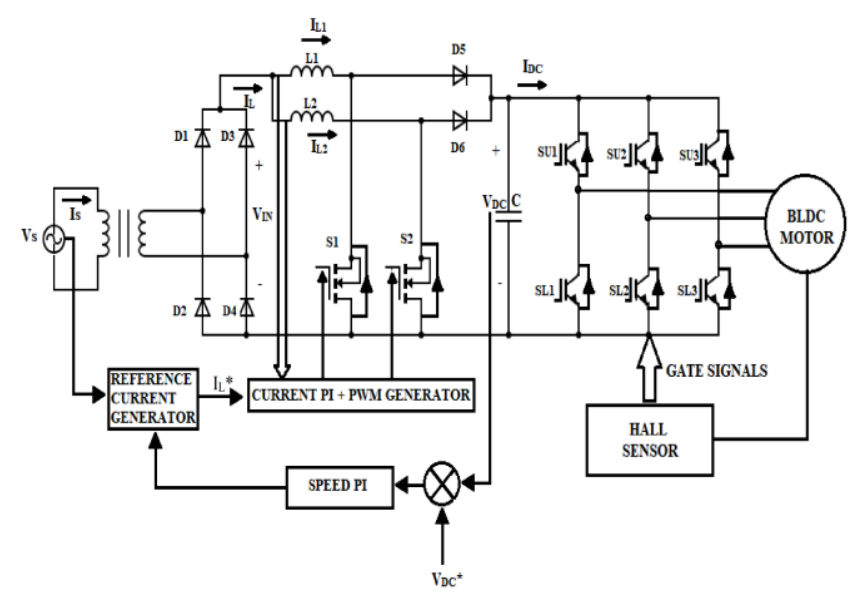

Fig. 1 - Schematic Diagram of the Voltage controlled power quality improvement system

The Interleaved boost converter which acts as a PFC converter has MOSFET as the power electronic device used for switching. The Inverter which excites the BLDC motor has Insulated Bipolar Gate Transistor (IGBT) as the switching device. Current multiplier approach is used for enhancing the power quality. It consists of Cascade loops i.e. speed control loop that acts as the outer loop and the current control loop which is a fast acting inner loop. The voltage across the capacitor of the Interleaved Boost converter is equivalent to the motor speed. This converter output voltage is fed back and is given to a comparator with a DC voltage reference $\left(\mathrm{V}_{\mathrm{DC}}{ }^{*}\right)$. The error obtained is given to a Speed PI controller that results in a current control signal $\left(\mathrm{I}_{\mathrm{C}}\right)$. This signal $\mathrm{I}_{\mathrm{C}}$ is multiplied by an absolute value of sine wave with unit value. This gives the Inductor current reference $I_{L} *$. The reference current obtained is given to a comparator with fed back inductor currents $\mathrm{I}_{\mathrm{L} 1}$ and $\mathrm{I}_{\mathrm{L} 2}$ of the converter. The error obtained is given to two Current PI controllers which give the modulating signals $\mathrm{m}_{\mathrm{d} 1}$ and $\mathrm{m}_{\mathrm{d} 2}$. These signals are then compared with a unit amplitude carrier of saw tooth shape wave having a constant frequency. One carrier wave has a phase delay of zero degree and another has a phase delay of $180^{\circ}$. This generates the Gating signals G1 and G2 for the converter switches. When the voltage reference $\mathrm{V}_{\mathrm{DC}} *$ is changed, the converter output voltage tracks the voltage reference. This DC link voltage is an equivalent of the motor speed. Hence by changing the reference to different voltage levels, the converter output voltage is adjusted thereby regulating the speed of the motor. 


\section{MODELLING OF VOLTAGE CONTROLLER BASED POWER QUALITY ENHANCER DRIVE}

The drive presented comprises of the following divisions-

A) PQ enhancer Block B) Inverter block

C) Controller Block.

\section{A. PFC Converter}

The proposed Converter used for improving the quality of power has the same calculations as it is for the boost converter. The voltage across output capacitor is calculated by -

$$
\mathrm{V}_{\mathrm{O}}=\mathrm{V}_{\mathrm{DC}}=\mathrm{V}_{\mathrm{IN}} /(1-\mathrm{D})
$$

Where, $\mathrm{D}$ is the duty ratio of the switches and $\mathrm{V}_{\text {IN }}$ is the average voltage of the bridge rectifier output. This acts as the supply to the interleaved converter. It is related to the stepped down input voltage $\mathrm{V}_{\mathrm{ST}}$ as -

$$
\mathrm{V}_{\mathrm{IN}}=2 \sqrt{ } 2 \mathrm{~V}_{\mathrm{ST}} / \pi
$$

The value of the boost inductors of the converter is calculated by-

$$
\begin{aligned}
& \mathrm{L}_{1}=\mathrm{DV}_{\mathrm{IN}} /\left\{\mathrm{f}_{\mathrm{S}}\left(\Delta \mathrm{I}_{\mathrm{L} 1}\right)\right\} \\
& \mathrm{L}_{2}=\mathrm{DV}_{\mathrm{IN}} /\left\{\mathrm{f}_{\mathrm{S}}\left(\Delta \mathrm{I}_{\mathrm{L} 1}\right)\right\}
\end{aligned}
$$

Where, $f_{s}$ is the frequency at which the switching of the individual switches occur. $\Delta \mathrm{I}_{\mathrm{L} 1}$ and $\Delta \mathrm{I}_{\mathrm{L} 2}$ are the inductor current ripples in the boost inductors $\mathrm{L}_{1}$ and $\mathrm{L}_{2}$ respectively. The inductor current is divided in the two branches. Hence the current across each inductor will be exactly half of the total inductor current.

The output capacitor value is calculated as -

$$
\mathrm{C}=\mathrm{DI}_{\mathrm{DC}} / \mathrm{f}_{\mathrm{S}}\left(\Delta \mathrm{V}_{\mathrm{O}}\right)
$$

Where, $\Delta \mathrm{V}_{\mathrm{O}}$ is the output voltage ripple and $\mathrm{I}_{\mathrm{DC}}$ is the DC link current which is the input current to the Three Phase Inverter.

The converter is designed for a DC link voltage $\mathrm{V}_{\mathrm{O}}=\mathrm{V}_{\mathrm{DC}}=300 \mathrm{~V}$ for an input voltage of $99 \mathrm{~V}$. The switching frequency of each switch is chosen as $10 \mathrm{kHz}$. The input inductor values and capacitor value obtained after calculation are $13.26 \mathrm{mH}$ and $0.724 \mathrm{mF}$ respectively.

\section{B. BLDC Motor Drive}

The BLDC Motor Drive consists of-
i) Hall sensor
ii)An Inverter
iii) BLDC motor

\section{i) Hall Sensor}

Motors like induction motor, synchronous motor etc., are mechanically commutated. But BLDC motor is electronically commutated by 3 position sensors called as Hall sensors. Table I illustrates the commutation sequence of the Hall sensors $[1,7,18]$. Depending on the output signal of the Hall sensors, the sequence of switching the Voltage source Inverter switches will be decided. Thereby the corresponding stator windings will be excited.

Table I - Commutation Sequence depending on Hall Sensor Output [1,7]

\begin{tabular}{|c|c|c|c|c|c|c|c|c|}
\hline \multicolumn{7}{|c|}{$\begin{array}{c}\text { Output of the } \\
\text { sensor }\end{array}$} & \multicolumn{7}{|c|}{ Sequence of switching } \\
\hline $\mathrm{H}_{\mathrm{a}}$ & $\mathrm{H}_{\mathrm{b}}$ & $\mathrm{H}_{\mathrm{c}}$ & $\mathrm{S}_{\mathrm{U} 1}$ & $\mathrm{~S}_{\mathrm{L} 1}$ & $\mathrm{~S}_{\mathrm{U} 2}$ & $\mathrm{~S}_{\mathrm{L} 2}$ & $\mathrm{~S}_{\mathrm{U} 3}$ & $\mathrm{~S}_{\mathrm{L} 3}$ \\
\hline 0 & 0 & 0 & 0 & 0 & 0 & 0 & 0 & 0 \\
\hline 0 & 0 & 1 & 0 & 0 & 0 & 1 & 1 & 0 \\
\hline 0 & 1 & 0 & 0 & 1 & 1 & 0 & 0 & 0 \\
\hline 0 & 1 & 1 & 0 & 1 & 0 & 0 & 1 & 0 \\
\hline 1 & 0 & 0 & 1 & 0 & 0 & 0 & 0 & 1 \\
\hline 1 & 0 & 1 & 1 & 0 & 0 & 1 & 0 & 0 \\
\hline 1 & 1 & 0 & 0 & 0 & 1 & 0 & 0 & 1 \\
\hline 1 & 1 & 1 & 0 & 0 & 0 & 0 & 0 & 0 \\
\hline
\end{tabular}

ii) Three Phase Voltage Source Inverter(VSI)

Fig. 2 shows the Voltage source Inverter to which the armature windings of the Brushless Direct Current motor are connected. It is operated in 120 degree conduction mode to excite the motor.

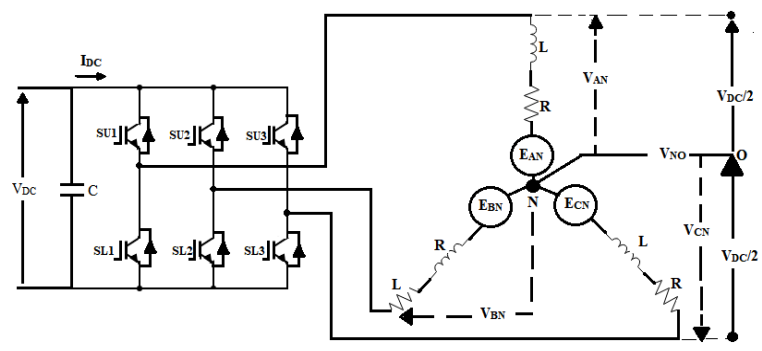

Fig 2. - Three Phase Voltage source Inverter

The phase voltages of $\mathrm{a}, \mathrm{b}$ and $\mathrm{c}$ phases are given by-

$$
\begin{aligned}
& V_{\text {PHASE }}=V_{D C} / 2 \text { for } S_{U}=1 \\
& V_{\text {PHASE }}=-V_{D C} / 2 \text { for } S_{L}=1 \\
& V_{\text {PHASE }}=0 \text { for } S_{L}=0 \text { and } S_{U}=0
\end{aligned}
$$

Where, $S_{U}$ represents the Upper leg switches. $S_{L}$ represents the Lower leg switches of the Inverter. $\mathrm{V}_{\mathrm{DC}}$ is the DC link voltage[13].

The values $1 \& 0$ depict the states "ON" and "OFF" of the Inverter IGBT switches.

\section{iii) BLDC Motor}

The Brushless Direct Current motor modelling is done using differential equations $[10,18]$ -

$\mathrm{V}_{\mathrm{X}}=\mathrm{I}_{\mathrm{X}} \mathrm{R}_{\mathrm{X}}+\mathrm{dI} \mathrm{I}_{\mathrm{X}} / \mathrm{dt}\left(\mathrm{L}_{\mathrm{X}}+\mathrm{M}\right)+\mathrm{E}_{\mathrm{X}}$

Where, " $\mathrm{x}$ " represents phases $\mathrm{a}, \mathrm{b}$ and $\mathrm{c}$.

$\mathrm{V}_{\mathrm{X}}$ represents the phase voltage in volts.

$\mathrm{I}_{\mathrm{X}}$ represents the phase current in amperes. 
$\mathrm{R}_{\mathrm{X}}$ represents the phase resistance in ohms.

$E_{X}$ represents the back emf generated in volts.

$\left(\mathrm{L}_{\mathrm{X}}+\mathrm{M}\right)$ represents the self-inductance and mutual inductance in Henry.

$\mathrm{T}_{\mathrm{E}}=\mathrm{T}_{\mathrm{L}}+\mathrm{J} \mathrm{d \omega} / \mathrm{dt}+\mathrm{B \omega}$

Where, $\mathrm{T}_{\mathrm{E}}$ is the motor torque in $\mathrm{Nm}$.

$\mathrm{T}_{\mathrm{L}}$ represents compressor load torque in Nm.[18]

$\mathrm{J}$ depicts moment of Intertia in $\mathrm{kgm}^{2}$.

$B$ represents the viscous damping in $\mathrm{Nms} /(\mathrm{rad})$

$\omega$ is the speed of the motor in $\mathrm{rad} / \mathrm{s}$.

$\omega=\mathrm{d} \theta / \mathrm{dt}$

$\omega_{\mathrm{r}}=(\mathrm{P} / 2)^{*} \omega$

Where, $\theta$ is the rotor position in degrees

The emf produced at stator can be implicated by a function of the rotor angle $(\theta)$ [7] as,

$E_{X}=K_{B} f_{X}(\theta) \omega_{r}[18]$

Where, $\mathrm{K}_{\mathrm{B}}$ represents the constant of stator emf in volts/(rad/s).[7] $f_{X}(\theta)$ implicates the rotor angle function. It has an upper and lower bound of \pm 1 . The value of this function at different positions of rotor at phase ' $a$ ' is given by [9]-

$\mathrm{f}_{\mathrm{A}}(\theta)=1$ for $0<\theta<120^{\circ}[10]$

$f_{A}(\theta)=\left[\left(180^{\circ}-\theta\right)-1\right] / 30^{\circ}$ for $120^{\circ}<\theta<180^{\circ}[10]$

$\mathrm{f}_{\mathrm{A}}(\theta)=-1$ for $180^{\circ}<\theta<300^{\circ}[10]$

$f_{A}(\theta)=\left[\left(180^{\circ}-\theta\right)-1\right] / 30^{\circ}$ for $180^{\circ}<\theta<360^{\circ}[10]$

$\mathrm{fb}(\theta)$ and $\mathrm{fc}(\theta)$ are identical to $\mathrm{fa}(\theta)$ having $120^{\circ}$ and $240^{\circ}$ phase difference respectively [18].

The electromagnetic torque i.e. motor torque is expressed as,

$T_{E}=K_{B}\left[f_{A}(\theta) I_{A}+f_{B}(\theta) I_{B}+f_{C}(\theta) I_{C}\right][18,19]$

Equations (9)-(18) depict the overall dynamic BLDC motor model.

Table II displays the specifications of the motor.

Table II - BLDC motor specifications [12]

\begin{tabular}{|l|l|}
\hline Rated power & $375 \mathrm{~W}$ \\
\hline Rated speed & $3000 \mathrm{rpm}$ \\
\hline Rated Torque & $1.2 \mathrm{Nm}$ \\
\hline Rated voltage & $300 \mathrm{~V}$ \\
\hline $\mathrm{K}_{\mathrm{E}}$ & $78 \mathrm{~V} / \mathrm{krpm}$ \\
\hline $\mathrm{K}_{\mathrm{T}}$ & $0.744 \mathrm{Nm} / \mathrm{A}$ \\
\hline Poles & 4 \\
\hline $\mathrm{R}_{\mathrm{s}}$ & $14.56 \Omega$ \\
\hline $\mathrm{L}_{\mathrm{s}}$ & $25.71 \mathrm{mH}$ \\
\hline Inertia(J) & $0.03 \mathrm{kgm}^{2}$ \\
\hline
\end{tabular}

\section{PFC CONTROLLER}

The PFC controller consists of three main components

a). a speed controller b) a current controller c) a PWM generator.

\section{a) Speed Controller}

PI controller is used as speed controller. It tracks the voltage reference and speed is equivalent of it. If $\mathrm{V}_{\mathrm{DC}} *(\mathrm{n})$ is the DC voltage reference [7]. $\mathrm{V}_{\mathrm{DC}}(\mathrm{n})$ is the DC link voltage at the nth time. The difference of the two voltages is given by -

$$
\mathrm{V}_{\mathrm{E}}(\mathrm{n})=\mathrm{V}_{\mathrm{DC}} *(\mathrm{n})-\mathrm{V}_{\mathrm{DC}}(\mathrm{n})[10]
$$

The PI controller output $I_{C}(n)$ at the nth instant is -

$I_{C}(n)=I_{C}(n-1)+K_{P}\left\{V_{E}(n)-V_{E}(n-1)\right\}+K_{I} V_{E}(n)[17]$

Where, $K_{P}$ is the gain of proportional term. $K_{I}$ is the gain of the integral term of the speed PI controller. The tuned gain parameters $K_{P}$ and $K_{I}$ for the speed controller in this model are 0.2 and 0.04 respectively.

The input inductor current reference $\mathrm{I}_{\mathrm{L}} *$ is created by performing multiplication with sine wave of unit amplitude to obtain the signal $\mathrm{I}_{\mathrm{C}}$.

$\mathrm{I}_{\mathrm{L}}^{*}=\mathrm{I}_{\mathrm{C}}(\mathrm{n}) * \mathrm{u}$

Where, " $u$ " is the unit value of the ac mains voltage, given by-

$\mathrm{u}=\mathrm{V}_{\mathrm{AC}} / \mathrm{V}_{\mathrm{A}} ; \mathrm{V}_{\mathrm{A}}=\mathrm{V}_{\mathrm{M}} ; \mathrm{V}_{\mathrm{AC}}=\left|\mathrm{V}_{\mathrm{M}} \sin \omega \mathrm{t}\right|$

Where, $\mathrm{V}_{\mathrm{M}}$ is the maximum amplitude of the mains supply in volts. $\omega$ is the mains frequency in radians per second.

\section{b) Current controller}

The inductor current reference $\mathrm{I}_{\mathrm{L}} *$ is compared with the current through both the inductors. The current errors $\mathrm{I}_{\mathrm{E} 1}$ and $\mathrm{I}_{\mathrm{E} 2}$ are given to current PI controllers which give the modulating signals $\mathrm{m}_{\mathrm{d} 1}$ and $\mathrm{m}_{\mathrm{d} 2}$.

$$
\begin{aligned}
& \mathrm{I}_{\mathrm{E} 1}(\mathrm{n})=\mathrm{I}_{\mathrm{L}} *(\mathrm{n})-\mathrm{I}_{\mathrm{L} 1}(\mathrm{n}) \\
& \mathrm{I}_{\mathrm{E} 2}(\mathrm{n})=\mathrm{I}_{\mathrm{L}} *(\mathrm{n})-\mathrm{I}_{\mathrm{L} 2}(\mathrm{n}) \\
& \mathrm{m}_{\mathrm{d} 1}(\mathrm{n})=\mathrm{m}_{\mathrm{d} 1}(\mathrm{n}-1)+\mathrm{K}_{\mathrm{P}}\left\{\mathrm{I}_{\mathrm{E}}-\mathrm{I}_{\mathrm{E} 1}(\mathrm{n}-1)\right\}+\mathrm{K}_{\mathrm{I}} \mathrm{I}_{\mathrm{E} 1}(\mathrm{n}) \\
& \mathrm{m}_{\mathrm{d} 2}(\mathrm{k})=\mathrm{m}_{\mathrm{d} 2}(\mathrm{k}-1)+\mathrm{K}_{\mathrm{P}}\left\{\mathrm{I}_{\mathrm{E}}-\mathrm{I}_{\mathrm{E} 1}(\mathrm{n}-1)\right\}+\mathrm{K}_{\mathrm{I}} \mathrm{I}_{\mathrm{E} 2}(\mathrm{n})
\end{aligned}
$$

The tuned gain parameters $\mathrm{K}_{\mathrm{P}}$ and $\mathrm{K}_{\mathrm{I}}$ for current controller in this model are 0.9 and 0.8 respectively.

\section{c) PWM generator}

The modulating signals $\mathrm{m}_{\mathrm{d} 1}$ and $\mathrm{m}_{\mathrm{d} 2}$ are compared with a saw tooth carrier wave $\mathrm{S}_{\mathrm{C}}$. This carrier wave has unit amplitude and fixed frequency. This generates the Gating signals $G_{1}$ and $G_{2}$ for the switches of the converter and is given as - 
if $\mathrm{m}_{\mathrm{dx}}>\mathrm{S}_{\mathrm{C}}$, then $\mathrm{S}_{\mathrm{X}}=1$ else $\mathrm{S}_{\mathrm{X}}=0$, where $\mathrm{m}_{\mathrm{dx}}$ represents the modulating signal for switch $S_{X}$. " 1 " and "0" represents the switching states "ON" and "OFF" of the MOSFET switches.

\section{GRAPHICAL ANALYSIS OF THE BLDC DRIVE}

Simulation for the BLDC drive is performed in MATLAB-SIMULINK software. The performance assessment of the drive is done for an Air conditioner compressor load having a load Torque of $1 \mathrm{Nm}$. The rated speed of the motor is considered as $3000 \mathrm{rpm}$ where a rated power of $375 \mathrm{~W}$ is obtained. By varying the DC voltage reference, the capacitor voltage of converter is tracked and thereby desired speed is obtained.

Fig. 3 shows the parameters of AC mains before the improvement of power quality. The current is in the pulsed form with very high amplitude. This could cause damage to the equipment connected to it.

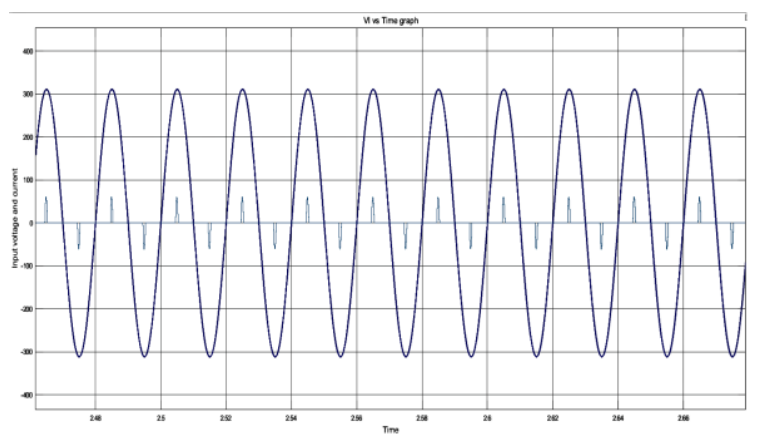

Fig. 3 - AC mains without power factor correction

Fig.4 displays the total schematic diagram of PFC controller system. It has the input block which consists of the AC mains supply, a step down transformer which would reduce the voltage. Diode bridge rectifier converts AC to pulsating DC voltage. The input block is connected to an interleaved boost converter block. This block is the input for inverter feeding the BLDC motor. The Hall sensor inputs are fed back to the inverter through a decoder block. This decides the sequence at which inverter IGBTs will switch. The controller block consists of a speed controller, a current controller and a PWM generator.

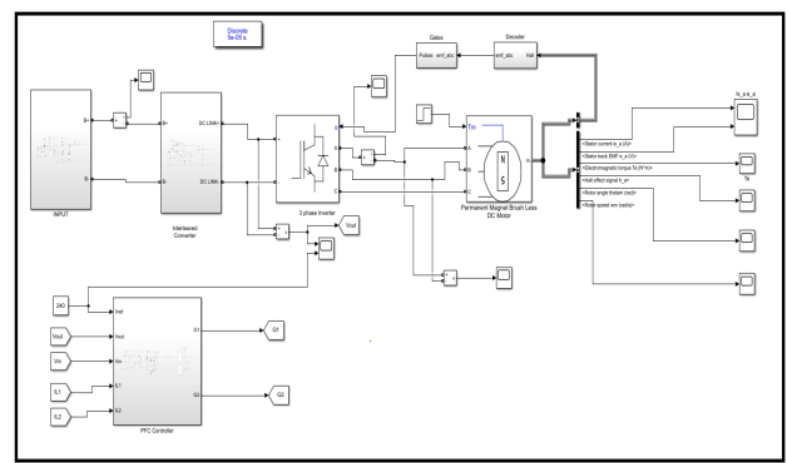

Fig. 4 - Block Diagram of the PFC controller system
Fig.5 implicates the PFC controller block which has speed PI controller, current PI controller and a PWM generator which is used to enhance the quality of power.

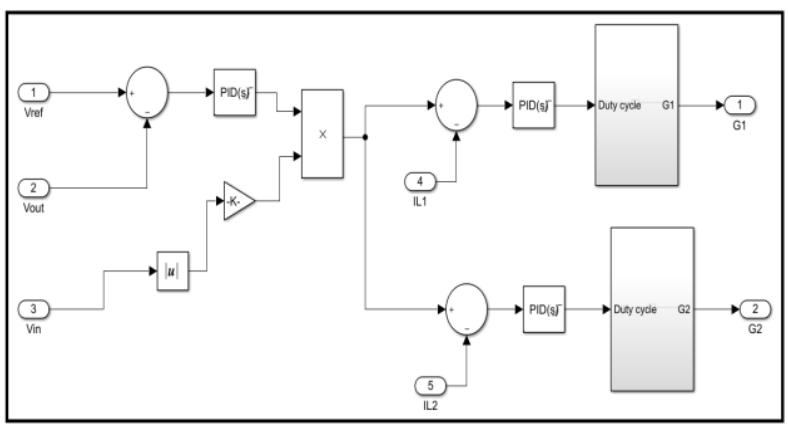

Fig. 5 - PFC controller inner circuitry

The simulation for BLDC motor is initially done for an output capacitor voltage of $300 \mathrm{~V}$ and a Rated current of $1.62 \mathrm{~A}$ with a Load torque maintained constant at $1 \mathrm{Nm}$.

Fig. 6 shows the graph of back EMF of all 3 phases for rated values. The back EMF is trapezoidal with 120 degree phase shift between each phase.
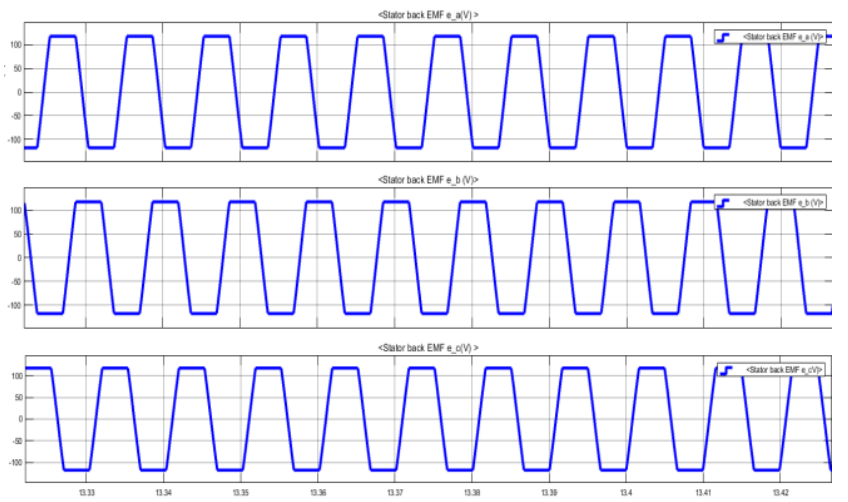

Fig. 6 - Stator emf of all three phases

Fig.7 shows the waveform of stator current of all three phases. The stator current is quasi rectangular in shape with 120 degree phase shift between each phase.

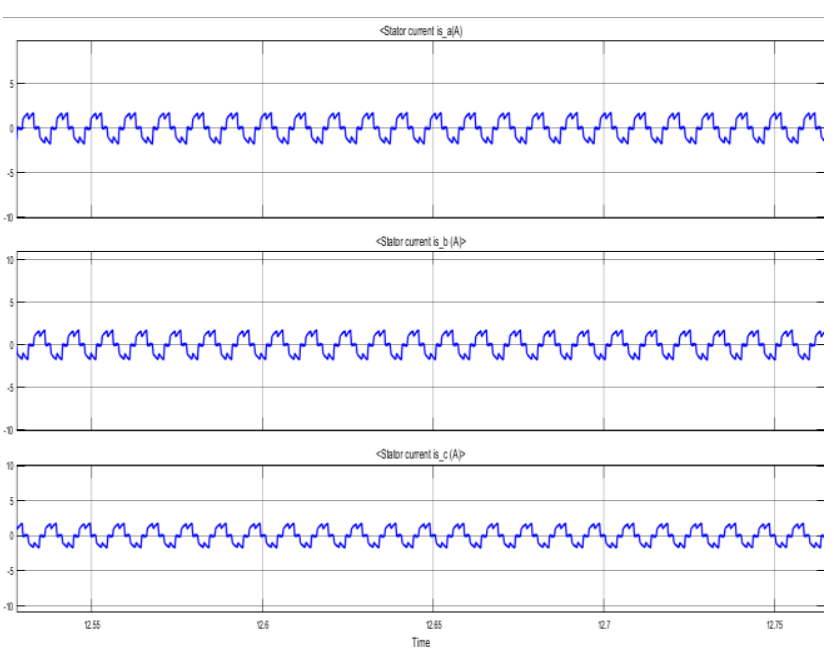


Fig. 7 - Stator current for all three phases

Fig. 8 shows the speed and torque waveforms at rated values.

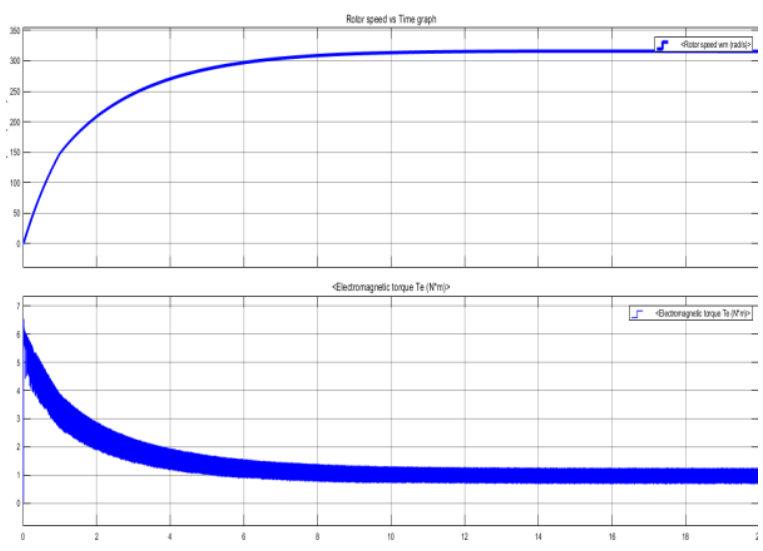

Fig. 8 - Speed and Torque waveforms

Fig.9 displays how the controller tracks the DC voltage reference $\mathrm{V}_{\mathrm{DC}} *$.

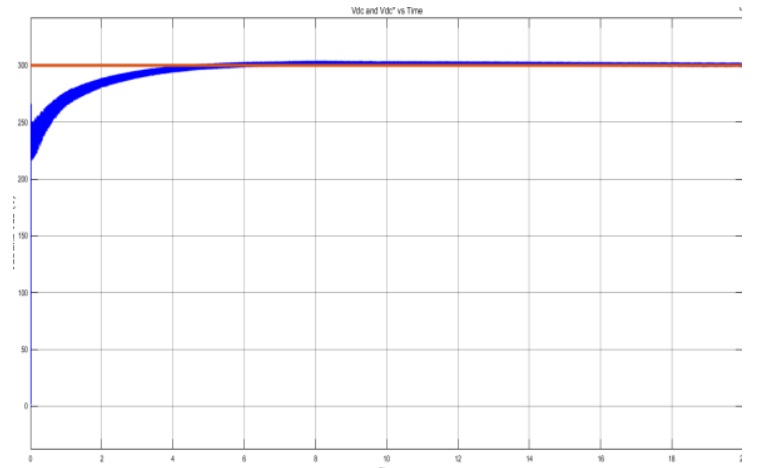

Fig. 9 - Tracking of the reference voltage by PI controller

Fig.10 illustrates the THD which the input supply current has and the harmonics at different frequencies. The THD is expected to be in the acceptable range according international standards of PQ IEC 61000-3$2[7,8,10,15]$.

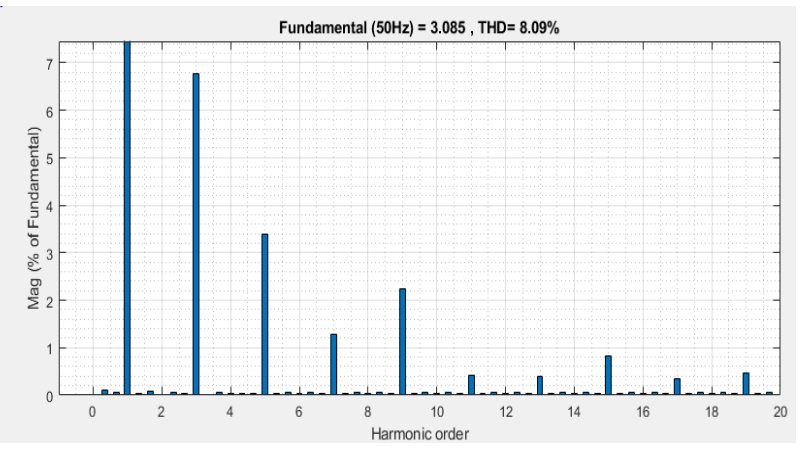

Fig. 10 THD of the input current

Fig.11 shows the waveform of parameters at AC mains after the power quality is improved. The current waveform is in phase with the voltage waveform to make the power factor nearer to 1 .

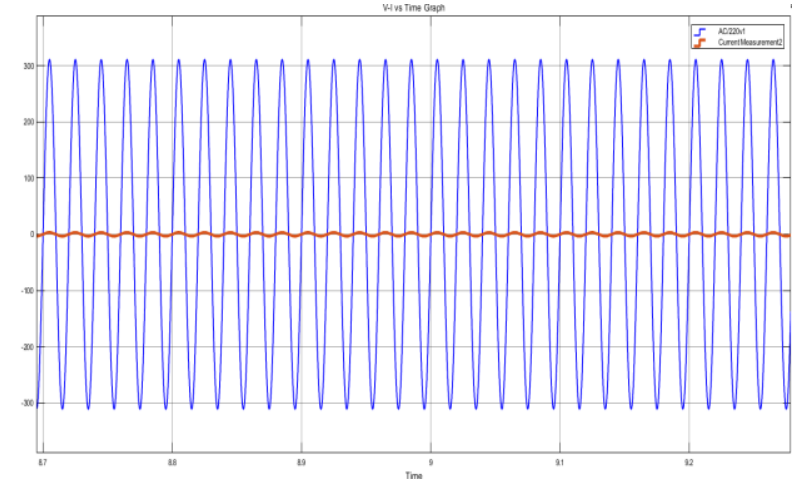

Fig 11 AC mains supply and current after PFC

Table III represents the overall aim of Speed control and Power Factor correction. A power factor of more than 0.99 is maintained for almost all the speeds and the values of the corresponding Back EMF generated is also tabulated.

TABLE III. Power Factor at mains supply for different motor speeds

\begin{tabular}{|l|c|c|l|l|}
\hline $\mathrm{V}_{\mathrm{DC}}$ & Speed(rpm) & EMF(V) & PF & THD \\
\hline 300 & 3000 & 117 & 0.9957 & $8.09 \%$ \\
\hline 285 & 2845 & 110 & 0.9949 & $8.12 \%$ \\
\hline 270 & 2670 & 104 & 0.9934 & $8.15 \%$ \\
\hline 255 & 2500 & 97 & 0.9932 & $8.21 \%$ \\
\hline 240 & 2330 & 91 & 0.9928 & $8.29 \%$ \\
\hline 225 & 2155 & 84 & 0.9919 & $8.41 \%$ \\
\hline 210 & 2000 & 77 & 0.9915 & $8.56 \%$ \\
\hline 195 & 1810 & 70 & 0.9912 & $8.74 \%$ \\
\hline 180 & 1640 & 64 & 0.9903 & $9.02 \%$ \\
\hline 165 & 1420 & 55 & 0.9897 & $9.47 \%$ \\
\hline 150 & 1290 & 50 & 0.9892 & $9.85 \%$ \\
\hline
\end{tabular}

\section{CONCLUSION}

Design and simulation of an interleaved converter fed BLDC motor drive has been analyzed using the MATLABSIMULINK software. The power factor, close to the desired value is achieved. Also the speed control of the motor is achieved for Air-conditioner compressor load application. The drive presented has exhibited an improvement in the quality of power at the supply end for different values of speed. The resulted PQ parameters are in the same range of that of Standard PQ values. Therefore, desired performance is obtained for the drive at different speeds with an increased quality of power. The results are very satisfactory and is suitable for application in an Air-conditioning system. 


\section{ACKNOWLEDGEMENT}

Authors are grateful to the Management, BMS Educational Trust, Principal and Vice-Principal, BMS College of Engineering.

\section{REFERENCES}

[1] Hamid Toliyat A. and Campbell Steven (2004), DSPBased Electromechanical Motion Control. Texas A\&M University College Station, Texas.

[2] Saini Sachin, Dhaked Dheeraj Kumar, Sharma Piyush (2018). A Comprehensive Review Of Different Control Techniques For The permanent Magnet Brushless Dc Motor Drives, in International Journal For Technological Research In Engineering.

[3] Ragu S (2014). Simulation of Speed Control of Brushless DC Motor for four Quadrant Operation, in International Journal for Research in Applied Science \& Engineering Technology (IJRASET).

[4] Arunkumar , Thangavel (2014). A Review Paper on Torque Ripple Reduction and Power Quality Improvement in Brushless DC Motor Drives, in International Electrical Engineering Journal (IEEJ), (pp. 1567-1575).

[5] Mishra Shivani, Thakur S.S., Phulambrikar S.P. (2015). Speed Control of PMBLDC Motor with the Help of PI Controller, in SSRG International Journal of Electrical and Electronics Engineering (SSRG-IJEEE).

[6] Xia Chang-liang, Permanent Magnet Brushless DC Motor Drives and Controls, Tianjin University, P.R. China.

[7] Singh Sanjeev, Singh Bhim (2012). A VoltageControlled PFC Cuk Converter-Based PMBLDCM Drive for Air-Conditioners, in IEEE Transactions on Industry Applications, Vol. 48, NO. 2, March/April 2012, (pp. 832838).

[8] Bist Vashist, Singh Bhim (2014). PFC Cuk Converter Fed BLDC Motor Drive", in IEEE Transactions on Power Electronics.

[9] Bayoumi E.H.E., Soliman H.M. (2007). PID/PI tuning for Minimal Overshoot of PM Brushless DC Motor Drive Using Swarm Optimization, (pp. 198-208).
[10] Athiyaman S, Prakasam K. (2013). Power Quality Improvement In PMBLDCM Drive Using PFC Sepic Converter For Air Conditioner, in International Journal of Engineering Sciences \& Research Technology, (pp. 16681674).

[11] Limits for Harmonic Current Emissions (Equipment Input Current $\leq 16$ A Per Phase), Int. Std. IEC 61000-3-2, 2000.

[12] Mathew Stephy, Nayana J. (2017). Review of DC-DC Converters for PFC in SMPS, in IOSR Journal of Electrical and Electronics Engineering, (pp. 35-43).

[13] Jayachandran Sonu, Pavana and Vinatha U. (2017). One Cycle Controlled Bridge-less SEPIC Converter Fed BLDC Motor Drive.

[14] Thiyagarajan A., Praveen Kumar S.G., Nandini A. (2014). Analysis and Comparison of Conventional and Interleaved DC/DC boost converter, in 2nd International Conference on Current Trends in Engineering and Technology, ICCTET'14, (pp. 198-205).

[15] Singh Bhim, Singh Sanjeev (2010). Power Factor Correction in Permanent Magnet Brushless DC Motor Drive Using Single-Phase Cuk Converter, in Journal of Engineering Science and Technology, (pp. 412-425).

[16] Singh Praveen Kumar, Singh Bhim, Bist Vashist, Chandra Kamal Al-Haddad, Ambrish (2017). BLDC Motor Drive Based on Bridgeless Landsman PFC Converter with Single Sensor and Reduced Stress on Power Devices, in IEEE Transactions on Industry Applications.

[17] Bhim Singh, Vashist Bist (2014). A BL-CSC Converter Fed BLDC Motor Drive with Power Factor Correction, in IEEE TRANSACTIONS ON INDUSTRIAL ELECTRONICS.

[18] Poovizhi M., Senthil Kumaran M., Ragul P., Irene Priyadarshini L., Logambal R. (2017). Investigation of mathematical modelling of brushless dc motor (BLDC) drives by using matlab-simulink, 2017 International Conference on Power and Embedded Drive Control(ICPEDC) 2017.

[19] Das Bikram, Chanda Mahua (2014). Torque Ripple Reduction and Speed Performance of BLDCM Drive with Hysteresis Current Controller, in International Journal of Engineering Research \& Technology, (pp 194-201). 